\title{
A Study of the Potentiality of use of Siwei Palm Midribs in Charcoal Production
}

\author{
Maysa Muhammad ${ }^{1, a^{*}}$, Hamed Elmously ${ }^{1, b}$ \\ ${ }^{1}$ Faculty of Engineering, Ain Shams University, 1 Elsarayat St., Abbaseya, 11517, Cairo, Egypt \\ aeng.maysa.asu@gmail.com, 'bamed.elmously@gmail.com
}

Keywords: charcoal production, Biochar production, palm midrib charcoal, production of charcoal from agriculture residues

\begin{abstract}
The objective of this study utilizes the residues of Siwei palm midrib to produce charcoal with satisfactory environmental, medical, and industrial applications. Choosing the Siwei palm midrib residues is based on its distribution all over Egypt and availability for Egyptian farmers. The study objective was achieved by passing with some steps. The first step prepared the samples, where used the Siwei palm midrib samples and then divided the Siwei palm midrib into five parts (top, middle, base, knee, and end), according to the dimension of the inner reactor. The second step is to design and manufactures a pyrolysis reactor (test rig) to produce charcoal. The third step is carbonization cycle process for the samples of Siwei palm midrib five parts with quantity for all part, where the carbonization cycle process steps according to food and agriculture organization (FAO) standard. The four-step is experimental analysis for ten samples of Siwei palm midrib five parts (row material before carbonization) and Siwei palm midrib five parts (after carbonization) in labs according to American society for testing and materials (ASTM) standards. The experimental analysis divided into proximate analysis such as (moisture content, ash content, volatility matter content, and fixed carbon content), ultimate analysis such as sulfur, and calorific value(also known as heating value or a specific value). Finally, after comparing the results of the experimental analysis for samples Siwei palm midrib parts (after carbonization) to FAO standard values. The potentiality of production of charcoal from Siwei palm midribs with satisfactory properties has been proven. The procedure charcoal is suitable for environmental, medical, and industrial applications. According to FAO, the best samples are the top part of palm midrib in Siwei, followed by the base, middle, knee, and end. The whole Siwei palm midrib could be utilized realizing the calorific value $88 \%$ of the FAO standard. The designed reactor in this work could serve as a model for the production of charcoal from palm midribs in the village conditions.
\end{abstract}

\section{Introduction}

The charcoal is the black carbon and ash residues, which come from animal or vegetation substances by removing water and volatile matter during slow heating in the absence of oxygen by pyrolysis process. Charcoal marketing shapes, the first lump charcoal is low ash, high calorific value, and ability to be used in many applications, the other briquette charcoal is high ash, medium calorific value, and ability to use in low energy applications. The charcoal applications are environmental, medical and industrial. The environmental applications are using the charcoal in soil amendment is considerably required, because it increases the carbon concentration in soil and reduces the emissions of green carbon gases. The medical applications with activated carbon mean that the carbon structure of the charcoal has a pore in low volume to do absorption of chemical substances. It acts as filters and has excellent health and medical benefits. The industrial applications have required the sulfur at low levels as much as possible to 
avoid environmental effects, the ash content at high to realize the most significant energy consumption, the stable pore structure, and chemical compatibility. Almost smokeless, because of its low ash content and chemical stability.

\section{Experimental Procedures}

Siwei Palm Midribs Specimens were obtained from Al-Qayat Village, Menia governorate, Egypt. (Fig. 1) illustrates the different parts of palm midrib including: Palm end left on the palm after pruning, the knee (the bent part of the palm midrib), difficult to manufacture, and the three parts of the midrib: base, middle and top.

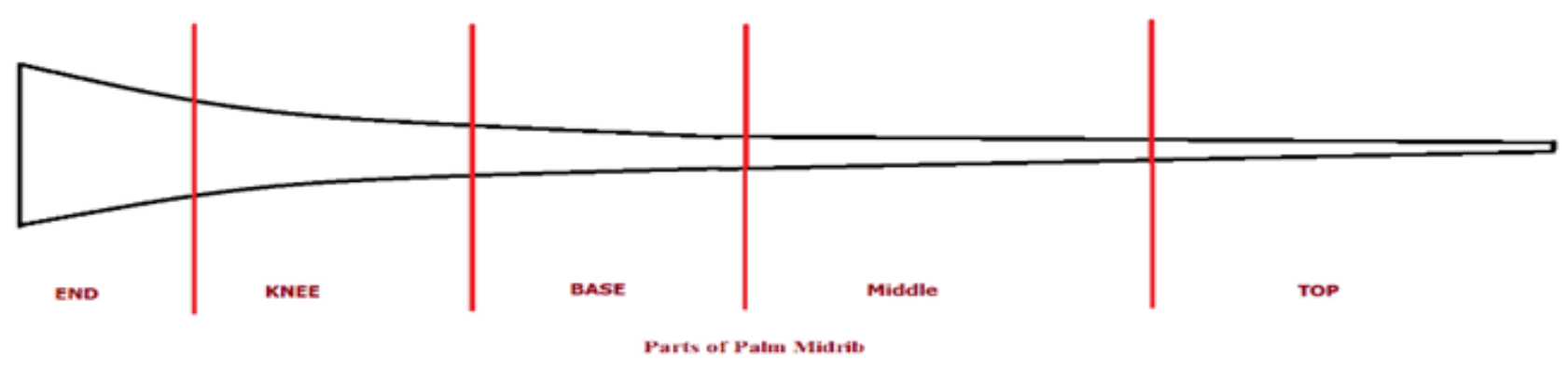

Fig. 1 Parts of Siwei palm midrib

The following test samples (Table1) have been sourced from Al-Qayat village, Menia Governorate, Egypt.

Table 1 Quantity of items

\begin{tabular}{cc} 
Item & Quantity (kg)* \\
\hline End & 3 \\
\hline Knee & 2 \\
\hline Base & 2 \\
\hline Middle & 2 \\
\hline Top & 1.5
\end{tabular}

*Air-dry weight

Test Rig (Pyrolysis Reactor) was considered the step to produce the charcoal from Siwei palm midrib parts. The pyrolysis reactor is consisting of three main assemblies, pyrolysis reactor assembly, control system, and condensing unit. The (fig.2) illustration the $3 \mathrm{D}$ assembly for pyrolysis reactor. The pyrolysis reactor assembly is a double wall chamber made of steel sheets with a thickness of $6 \mathrm{~mm}$, and its capacity is about $120 \mathrm{~L}$, where take into consideration the space between species. The outer dimension of the reactor is $70 \mathrm{~cm} \times 70 \mathrm{~cm} \times 95 \mathrm{~cm}$, and the inner dimension is $40 \mathrm{~cm} \times 40 \mathrm{~cm} \times 65 \mathrm{~cm}$, where the isolation layers exist made of ceramic fiber to isolate the inner kiln. The inner kiln is supported with three heaters in three different positions, at all side one and in bottom one. The reactor has a door and fixes the thermocouple with weldment in 
the door to measure the carbonization process (inner reactor). The pyrolysis reactor assembly is connected to a central pipe to condensing unit. The central pipe in the chamber takes out the evolved gases and vapers directly through a condenser unit.

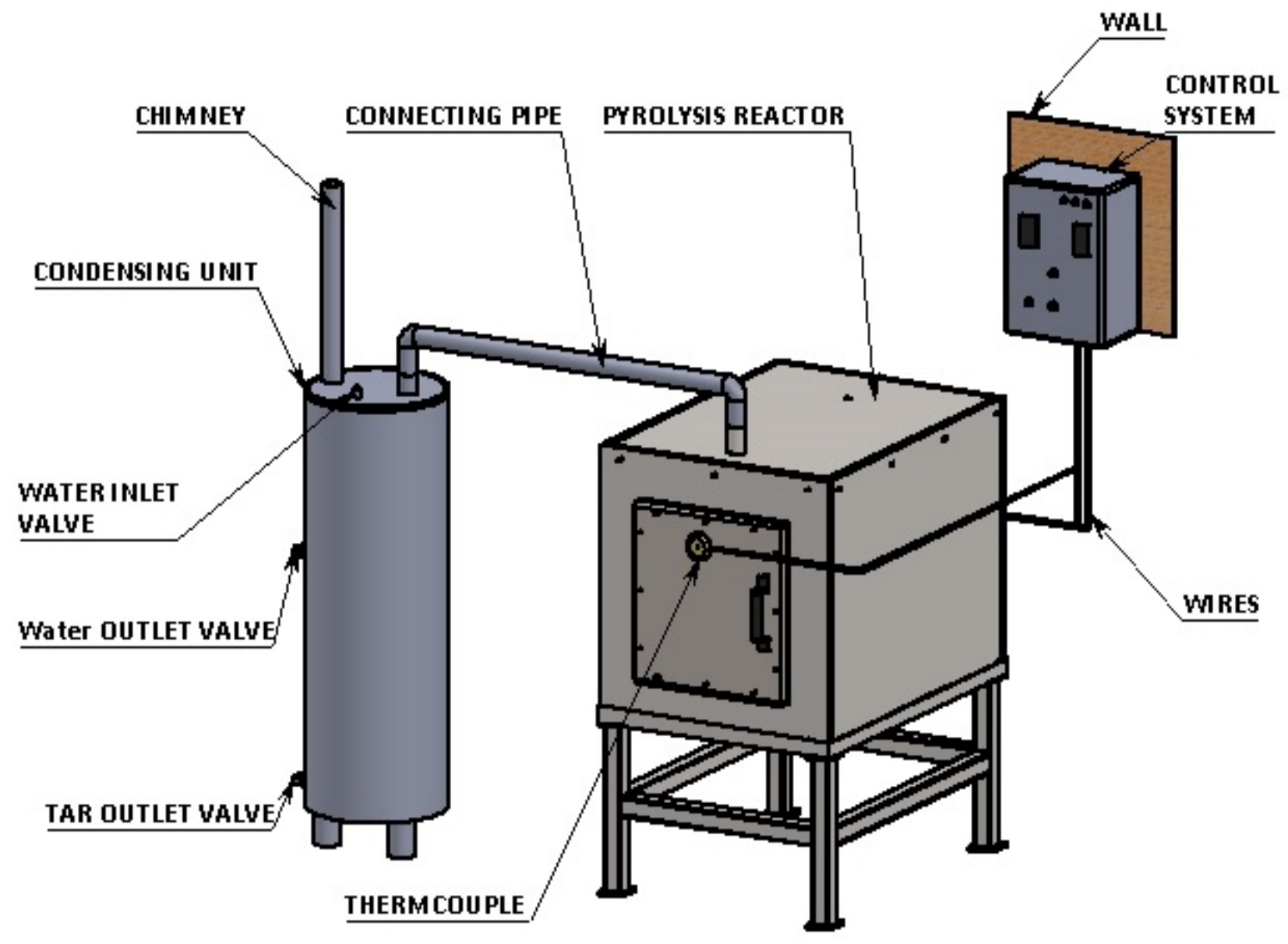

Fig.2 A Sketch of the pyrolysis reactor used in the research

Carbonization Cycle Method by pyrolysis process, and slow heating rate around $5-7^{\circ} \mathrm{C} / \mathrm{min}$. Until reaching $400-500^{\circ} \mathrm{C}$. The method of heat with pyrolysis process in the study is indirect heating. The process includes stages of carbonization cycle according to food and agriculture organization (FAO) standards. The process includes the following stages: At temperatures between $100-120^{\circ} \mathrm{C}$, drying of the input material and moisture goes out. At around $275^{\circ} \mathrm{C}$ gases like N2, CO, and CO2, go out. Also, methanol is distilled. Around between temperatures of 280 $-350{ }^{\circ} \mathrm{C}$, exothermic chemical reactions. At more than $350{ }^{\circ} \mathrm{C}$ biochar remains, $\mathrm{H} 2$ reacts with $\mathrm{CO}$ and goes out in the form of tar. The (Table.2) and (Fig.3), illustrate a sample of the carbonization cycle for the top part of the Siwei palm midrib. 
Table 2 Carbonization cycle of Siwei palm midrib (top part)

\begin{tabular}{ccc}
\hline Time (min.) & Temperature $\left({ }^{\circ} \mathbf{C}\right)$ & Remarks \\
\hline $\mathbf{0}$ & 33 & \\
\hline $\mathbf{6}$ & 38 & \\
\hline $\mathbf{1 2}$ & 66 & \\
\hline $\mathbf{2 4}$ & 123 & \\
\hline $\mathbf{3 0}$ & 180 & \\
\hline $\mathbf{3 6}$ & 257 & \\
\hline $\mathbf{4 2}$ & 315 & \\
\hline $\mathbf{4 8}$ & 363 & \\
\hline $\mathbf{5 4}$ & 389 & \\
\hline $\mathbf{6 0}$ & 423 & \\
\hline $\mathbf{6 6}$ & 447 & \\
\hline $\mathbf{7 2}$ & 463 & \\
\hline $\mathbf{7 4}$ & 490 & \\
\hline & 501 & \\
\hline & & \\
\hline
\end{tabular}

\section{Top Part Pyrolysis Temp. - Time Graph}

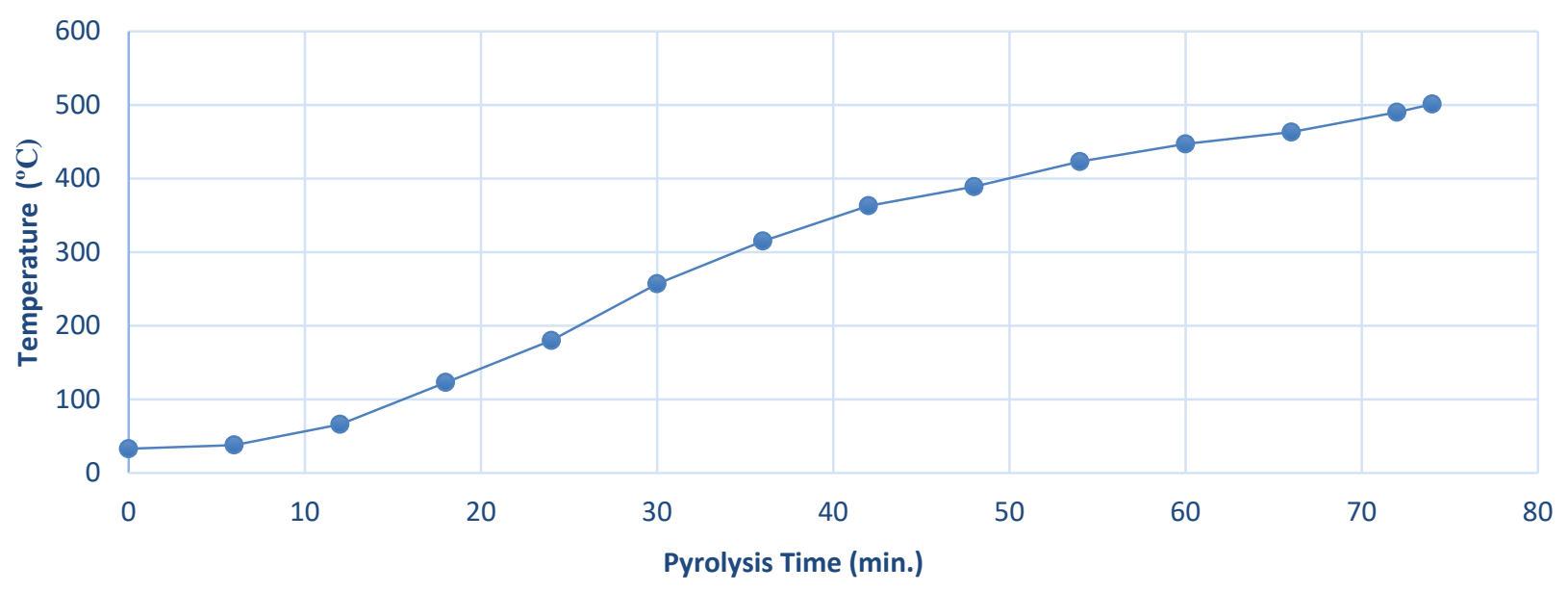

Experimental Analysis Method is standard chemical laboratory analysis is done up samples of the Siwei palm midrib parts (raw material), and the Siwei palm midrib parts (after carbonization cycle). The experimental analysis is calculated according to American society for tooling and materials (ASTM) standard. This experimental analysis determines the charcoal quality and suitability to be used in environmental, medical, and industrial applications. The tests were carried out, proximity analysis, ultimate analysis, and specific energy analysis. The current work of the experimental analysis of the palm midrib parts is done at agriculture research center (ARC). The proximity analysis is divided into the analysis of moisture content, the analysis of volatile matter content, the analysis of ash content, and the analysis of fixed carbon. The ultimate analysis is an analysis of sulfur content. The specific energy analysis is an analysis of the calorific value. 


\section{Results and Discussions}

The results of the experimental analysis are according to ASTM standard for Siwei palm midrib parts after carbonization cycle, and Siwei palm midrib parts (raw material) are a shown in (table. 3). These results are significant to the limited quality of all part of Siwei palm midrib after carbonization, and its application is suitable for each part. As for the Siwei palm midrib parts (raw material), results are compared to the Siwei palm midrib parts after carbonization to illustrate the changes, which occur for chemical and physical composition of Siwei palm midrib under pyrolysis process.

Table 3 Results of analysis for Siwei palm midrib parts after carbonization

\begin{tabular}{cccccccc}
$\begin{array}{c}\text { Specimen } \\
\text { No. }\end{array}$ & $\begin{array}{c}\text { Specimen } \\
\text { Name }\end{array}$ & $\begin{array}{c}\text { Calorific } \\
\text { Value } \\
\mathbf{k J} / \mathbf{k g}\end{array}$ & $\begin{array}{c}\text { Fixed } \\
\text { Carbon } \\
\mathbf{\%}\end{array}$ & $\begin{array}{c}\text { Volatile } \\
\text { Matter } \\
\mathbf{\%}\end{array}$ & $\begin{array}{c}\text { Ash } \\
\text { Content } \\
\mathbf{\%}\end{array}$ & $\begin{array}{c}\text { Sulfur } \\
\text { Content } \\
\mathbf{\%}\end{array}$ & $\begin{array}{c}\text { Moisture } \\
\text { Content \% }\end{array}$ \\
\hline $\mathbf{1}$ & Siwei End & 23,300 & 40.74 & 22.90 & 34.29 & 0.23 & 3.09 \\
\hline $\mathbf{2}$ & Siwei Knee & 24,800 & 38.88 & 28.25 & 31.65 & 0.12 & 1.09 \\
\hline $\mathbf{3}$ & Siwei Base & 27,000 & 48.84 & 29.42 & 20.49 & 0.11 & 2.29 \\
\hline $\mathbf{4}$ & Siwei Middle & 25,700 & 56.61 & 27.42 & 15.30 & 0.12 & 1.87 \\
\hline $\mathbf{5}$ & Siwei Top & 28,600 & 57.36 & 26.89 & 14.94 & 0.14 & 1.82 \\
\hline $\mathbf{6}$ & $\begin{array}{c}\text { Average of } \\
\text { palm midrib }\end{array}$ & $\mathbf{2 5 , 9 0 0}$ & $\mathbf{4 8 . 8 4}$ & $\mathbf{2 6 . 9 8}$ & $\mathbf{2 3 . 3 3}$ & $\mathbf{0 . 1 5}$ & $\mathbf{2 . 1 9}$ \\
& & & & & & \\
\hline
\end{tabular}

By comparison the calorific value, fixed carbon, volatile matter, ash content, sulfur content, and moisture content experimental analysis results for Siwei palm midrib parts after carbonization concerning FAO lower and higher limits. The Siwei palm midrib parts after carbonization are accepted to produce charcoal. These differences in results of midrib parts are referred to fiber ratio of the chemical composition of midrib, where the top, middle, and base parts have fiber ratio large then knee and end. The percentage of calorific value concerning FAO lower limits. The average Siwei palm midrib charcoal is $88.39 \%, 97.74 \%$ for the top part, $87.76 \%$ for the middle part, $92.07 \%$ for base part, $84.84 \%$ for knee part, and 79.51 for end part, where FAO higher limits are not verified. The percentage of fixed carbon concerning FAO lower limits. The average Siwei palm midrib charcoal is $97.68 \%, 114.72 \%$ for the top part, $113.22 \%$ for the middle part, $97.68 \%$ for base part, $77.76 \%$ for knee part, and for $81.48 \%$ for end part, where FAO higher limits are not verified. The top, base, and middle parts are more suitable parts for the industrial application. (Fig.4) illustrates the calorific value and fixed carbon of Siwei palm midrib parts after carbonization and the lines of FAO standard with upper and lower limits. 

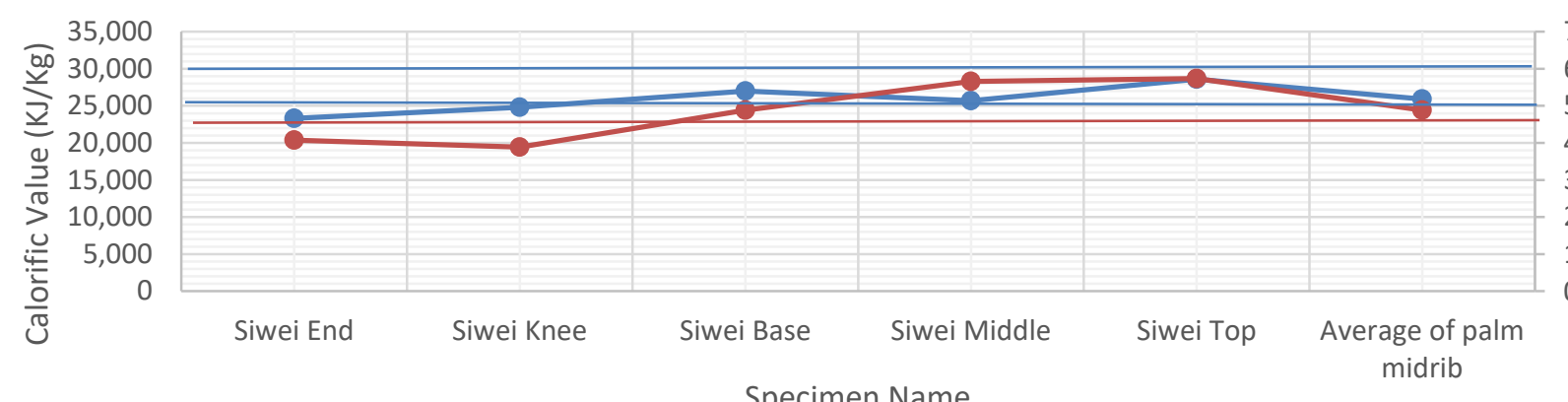

\section{Specimen Name}

$\longrightarrow$ Calorific Value $(\mathrm{KJ} / \mathrm{Kg}) \quad$ Fixed Carbon \%

Fig. 4 Calorific value and fixed carbon of Siwei palm midrib parts (After carbonization)

The percentage of the volatile matter concerning FAO lower limits for all parts are verified. AS for FAO higher limits, the average Siwei palm midrib charcoal is $67.45 \%, 67.23 \%$ for the top part, 68.55 for the middle part, $73.55 \%$ for base part, $70.63 \%$ for knee part, and $57.25 \%$ for end part. The middle and top parts are more parts suitable for the environmental application. The percentage of ash content concerning FAO lower and higher limits are not verified. However, can edit these results by reducing the carbonization temperature to $450^{\circ} \mathrm{C}$. (Fig.5) illustrates the volatile matter and the ash content for Siwei palm midrib parts after carbonization and the lines of FAO standard with upper and lower limits.

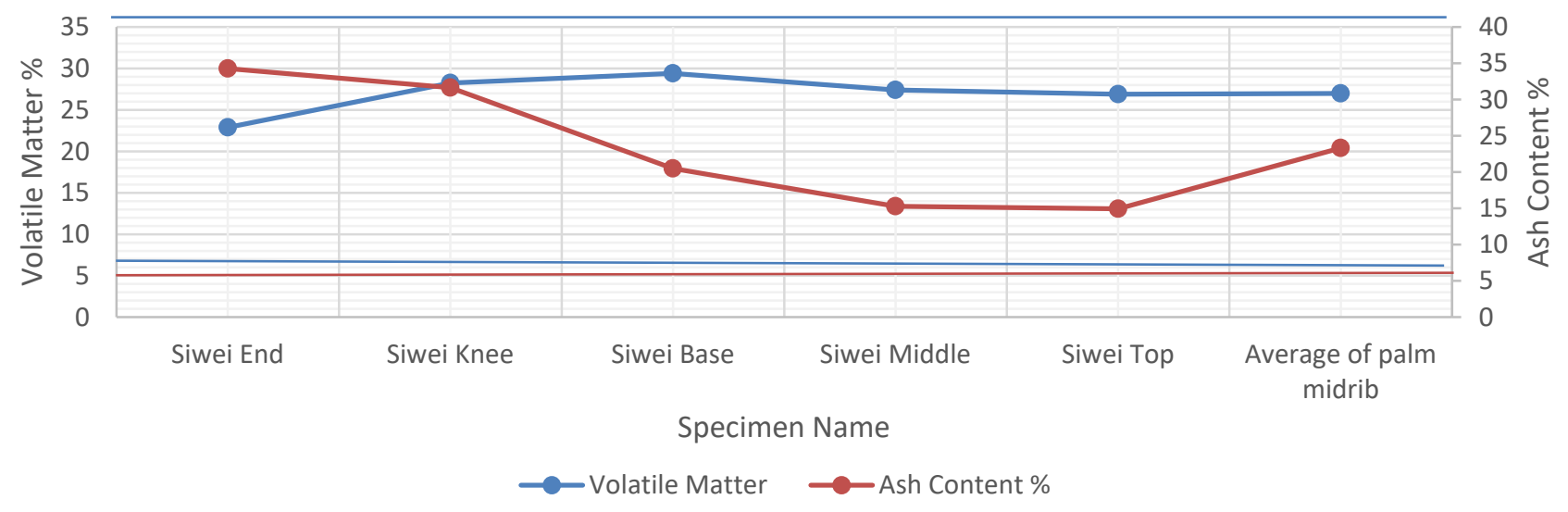

Fig. 5 Volatile matter and ash content of Siwei palm midrib parts (After carbonization)

Fig. 6 is shown the sulfur content, and moisture content concerning FAO lower and higher limits are verified, where the impact on the environment is positive. 


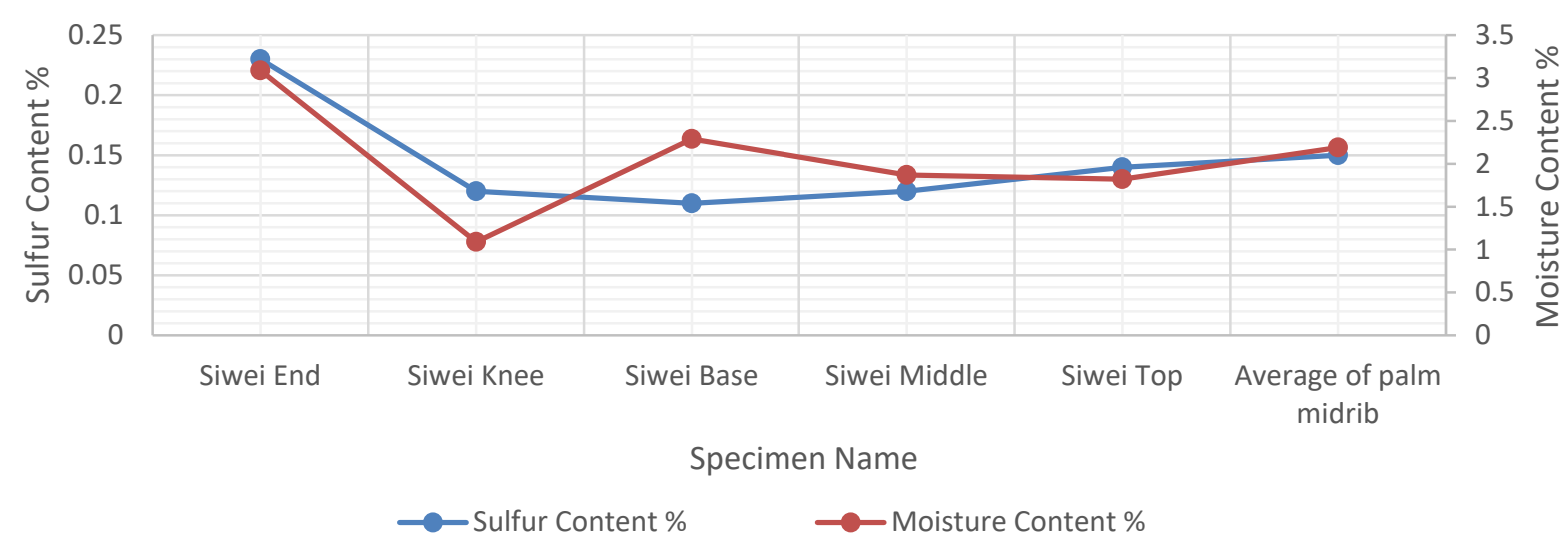

Fig. 6 Sulfur content and moisture content of Siwei palm midrib parts (After carbonization)

\section{Summary}

From the current study, the following conclusions, the potentiality of production of charcoal from Siwei palm midribs with satisfactory properties has been a proven. According to FAO, the best samples are the top part of palm midrib in Siwei, followed by the base, middle, knee, and end. The whole Siwei palm midrib could be utilized realizing the calorific value $88 \%$ of the FAO standard. The designed reactor in this thesis could serve as a model for the production of charcoal from palm midribs in the village conditions.

\section{References}

[1] John Twidell, Tony Weir, Renewable energy resources, Taylor and Francis, 2006.

[2] Global Status Report, Renewable Energy Policy Network for the 21st Century, Renewables, 2017.

[3] Atanu Mukherjee and Rattan Lal, Biochar impacts on soil physical properties and greenhouse gas emissions, Agronomy, 2013. https://doi.org/10.3390/agronomy3020313

[4] Ramadan A. Nasser, Evaluation of the use of midrib from common Date Palm cultivars grown in Saudi Arabia for Energy Production, Saudi Arabia, 2014.

https://doi.org/10.15376/biores.9.3.4343-4357

[5] Hassan A. Gomaa, Peter Steele, and Yousef A. Hamdy, Charcoal in Egypt, FAO Project, 2011.

[6] Hassan K.M. Bakheit and Magdi Latif, Date palm in Egypt, Egypt, 2015.

[7] Julije Domac and Miguel Trossero, Industrial charcoal production, FAO, 2008.

[8] William McDonough, The Hannover principles, design for sustainability, 1992.

[9] Sean Case, Biochar amendment and greenhouse gas emissions from agricultural soils, 2013.

[10] Public Par, Methods for producing biochar and advanced biofuels, 2017.

[11]Robert Prins, Wayne Teel, John Marier, Geoff Austin, Tim Clark, and Brandon Dick, Design, construction, and analysis of a farm scale biochar production system, Washington, 2011. [12] Stefan Czernik, Fundamentals of charcoal production, National bioenergy center, 2010. 